\title{
The characterization of plasmids in the enterobacteria
}

\author{
By E. S. ANDERSON AND E. J. THRELFALL \\ Enteric Reference Laboratory, Public Health Laboratory Service, \\ Colindale Avenue, London, NW9 5HT, England
}

(Received 26 October 1973)

\section{SUMMARY}

The routine methods used in the Enteric Reference Laboratory for the study of enterobacterial plasmids are described. The results of their application to plasmids of diverse origin, and their value for the categorization of those plasmids, are presented and discussed.

\section{INTRODUCTION}

Plasmids in the enterobacteria mediate the transfer of a variety of genetic determinants, including those for drug resistance, haemolysin and enterotoxin synthesis, colicinogeny, heavy metal tolerance, resistance to ultra-violet irradiation, carbohydrate fermentation, $\mathrm{H}_{2} \mathrm{~S}$ synthesis and other metabolic characters. The drug resistances transferred include those to ampicillin, carbenicillin, cephalosporins, chloramphenicol, neomycin-kanamycin, streptomycin, sulphonamides, tetracyclines, gentamicin and trimethoprim.

Transfer systems have been characterized and classified by various methods in different laboratories. However, standard methods of plasmid characterization are needed to compare transfer systems from different sources. Such comparisons may ultimately furnish information about the phylogenetic relationships and origins of the plasmids concerned, and about their host bacteria.

In the Enteric Reference Laboratory (ERL), we have studied many transfer systems of enterobacteria from human and animal sources. These have been routinely characterized by the examination of the following properties:

1. The range of resistances in the wild host strain.

2. The range of resistances transferred from that strain to 'standard' recipient strains.

3. The possible multiplicity of plasmids present in a strain.

4. The presence and identity of colicinogeny.

5. The class of resistance factor ( $R$ factor) involved, that is, whether it belongs to Class 1 , in which the resistance determinant and transfer factor are covalently bonded to form a single plasmid; or whether it is a Class 2 system, in which the resistance determinant ( $R$ determinant) and transfer factor form distinct plasmids, possibly associated only during transfer (Anderson, 1968, 1969; Anderson \& Threlfall, 1970; Anderson \& Natkin, 1972; Humphreys, Grindley \& Anderson, 1972). 
6. The transfer kinetics of the plasmid(s).

7. The mobilization of non auto-transferring (= non-transferring) resistance determinants in the strains by 'standard' transfer factors (Anderson, 1965a, $b$ ).

8. The determination of whether the plasmids enable their hosts to support multiplication of known donor-specific phages (Grindley \& Anderson, 1971).

9. The compatibility group(s) of the plasmid(s) present in the wild strain (Hedges \& Datta, 1971; Datta \& Hedges, 1971; Chabbert et al. 1972; Grindley, Grindley \& Anderson, 1972; Grindley, Humphreys \& Anderson, 1973).

10. The fertility inhibition $(f i)$ character (Egawa \& Hirota, 1962; Watanabe \& Fukasawa, 1962; Watanabe, Fukasawa \& Takano, 1962; Watanabe, 1963; Watanabe et al. 1964).

11. Phage restriction in Escherichia coli $\mathrm{K} 12$ ( = K12) and salmonellas (Anderson, 1966; Anderson, Threlfall, Carr \& Savoy, 1973).

12. The degrees of drug resistance conferred by $R$ factors or $R$ determinants.

13. The molecular characteristics of the plasmid DNA.

In this article we shall describe the application of these methods of characterization to nine transfer systems.

\section{Media}

\section{MATERIALS AND METHODS}

Liquid media for the growth of bacterial cultures contained 20 g. Bacto dehydrated nutrient broth (Difco Laboratories) and $8.5 \mathrm{~g}$. NaCl/1.; for solid media, 13 g./l. of Davis New Zealand powdered agar was added. Lactose and non-lactose fermenting cultures were differentiated by plating on Oxoid MacConkey agar.

\section{Bacterial strains}

The laboratory strains used in these studies are listed in Table 1.

\section{Bacteriophages and phage-typing}

The donor-specific phages for F- and I-specificity determination were $\mu 2$ (Dettori, Maccacaro \& Piccinin, 1961) and If1 (Meynell \& Lawn, 1968) respectively. The receptors for these phages are the $F$ and I sex fimbriae respectively.

Phage restriction in $\mathrm{K} 12$ was tested with the 'female-specific' phage $\phi 2$ of Cuzin (1965) (Pitton \& Anderson, 1970).

Phage restriction in salmonellas was investigated by phage-typing the respective strains. S.typhimurium was phage-typed by the methods of Callow (1959) and Anderson (1964, and in preparation); $S$.typhi carrying transfer systems was phage-typed according to Craigie \& Yen $(1938 a, b)$ and Craigie \& Felix (1947); and $S$. paratyphi $B$ by the method of Felix \& Callow $(1943,1951)$ and Anderson, (1964). The relevant techniques were summarized by Anderson \& Williams (1956).

\section{Drug resistance}

Resistance to ampicillin (A), chloramphenicol (C), gentamicin (G), neomycinkanamycin $(\mathrm{K})$, streptomycin $(\mathrm{S})$ and tetracyclines $(\mathrm{T})$ was routinely tested for by a diffusion method on nutrient agar plates, using strips of blotting paper (Ford's 
Table 1. Laboratory strains used as donors and recipients

ERL No.

14R525

19R689

26R862

B1363

RT641

$1 \mathrm{R380}$

22R 149

22R81

18R951

27R207

40R880

20R770

38R778

\section{Genotype}

E. coli $\mathrm{K} 12 \mathrm{~F}-l a c+\mathrm{Nx}^{\mathrm{r}}$

S. typhimurium phage type $36 \mathrm{Nx}^{\mathrm{r}}$

S. typhi Vi-phage type A $\mathrm{Nx}^{\mathrm{r}}$

$S$. paratyphi $B$ phage type 1 var. 2

S. typhimurium phage type $6 \Delta^{+}$

E. coli $\mathrm{K} 12 \mathrm{~F}-\mathrm{lac}^{+} \Delta^{+}$

S. typhimurium phage type $125 \mathrm{Str}^{\mathrm{r}} \mathrm{ColI}{ }^{+}$

E. coli $\mathrm{K} 12 \mathrm{~F}-$ lac $^{+} \mathrm{Str}^{\mathrm{r}} \mathrm{ColI}^{+}$

E. coli $\mathrm{K} 12 \mathrm{~F}-$ lac $^{-} \mathrm{Str}^{\mathrm{r}} \mathrm{X}^{+}$

E. coli $\mathrm{K} 12 \mathrm{HfrH} \mathrm{Nx}^{\mathrm{r}}$

$E$ coli $\mathrm{K} 12 \mathrm{~F}^{+}$

E. coli $\mathrm{K} 12$ F-lac ${ }^{+} \mathrm{T}-\Delta d r p 1^{+}$

E. coli K12 F-lac ${ }^{+}$R-144-3+
Plasmid

carried

$\begin{array}{cl}- & \text { K12 } \\ - & \text { Type 36 } \\ - & \text { S.typhi type A } \\ - & \text { S. paratyphi B } \\ & \text { type 1 var. } 2 \\ \Delta & \text { Type } 6 \Delta^{+} \\ \Delta & \text { K12 } \Delta^{+} \\ \text {ColI } & \text { Type } 125 \text { ColI } \\ \text { ColI } & \text { K12 ColI } \\ \text { X } & \text { K12 X+ } \\ \text { F } & \text { K12HfrH } \\ \text { F } & \text { K12 F+ } \\ \text { T- } \Delta d r p 1^{+} & \text {K12 T- } \Delta d r p 1 \\ \text { R144-3 } & \text { K12 R144-3 }\end{array}$

\section{Symbols}

$\mathrm{Nx}^{\mathrm{r}}=$ chromosomal resistance to nalidixic acid.

$\operatorname{Str}^{\mathbf{r}}=$ chromosomal resistance to streptomycin.

\section{Plasmid designation}

$\Delta=\Delta$ transfer factor (Anderson \& Lewis, 1965b).

$\mathrm{T}-\Delta=$ tetracycline $\mathrm{R}$ factor (Anderson \& Lewis, 1965b).

ColI = ColI-P9 factor (Fredericq, 1956).

$\mathrm{X}=f^{+}$F-like transfer factor from S.typhimurium 5M4136 (Anderson et al. 1968).

$\mathbf{F}=\mathbf{F}$ factor.

$\mathrm{T}-\Delta \operatorname{drp} 1=$ derepressed mutant of T- $\Delta$ (Grindley \& Anderson, 1971).

R144-3 = derepressed mutant of the I-like R factor R144 (Meynell \& Datta, 1967). R144 was isolated from S. typhimurium 4M91, characterized in the Enteric Reference Laboratory in 1964 (Anderson \& Datta, unpublished).

428 Mill) $80 \mathrm{~mm} \times 7 \mathrm{~mm}$ impregnated with the respective drugs and freeze-dried. These strips were prepared in the Enteric Reference Laboratory. The cultures were streaked at right angles to the antibiotic strips, and control sensitive and resistant cultures were included in each test. This method not only detects resistance, but enables its magnitude to be roughly compared with that of other cultures on the same plate (see Plate 1). Resistance to sulphonamides and trimethoprim was detected by spotting $0.01 \mathrm{ml}$. drops of a $10^{-4}$ dilution of a late exponential phase broth culture of the test strain on nutrient agar containing $5 \% \mathrm{v} / \mathrm{v}$ of lysed horse blood, and either $100 \mu \mathrm{g} . / \mathrm{ml}$. of sulphathiazole or $0.5 \mu \mathrm{g} . / \mathrm{ml}$. of trimethoprim (see Plate 2, Figs. 1 and 2). Sensitive and resistant controls were always included. Nalidixic acid resistance was also detected by this method, the nutrient agar containing $40 \mu \mathrm{g} . / \mathrm{ml}$. of the drug (see Plate 2, Figs. 3 and 4). Screening for furazolidone resistance was effected by spotting $0.01 \mathrm{ml}$. of undiluted culture of the strain on nutrient agar containing $100 \mu \mathrm{g} . / \mathrm{ml}$. of the drug.

\section{Colicinogeny}

Colicinogeny was detected by the agar-overlay method of Fredericq (1948), using $\mathrm{K} 12$ as the indicator strain. Colicins were identified on the basis of the 
immunity of standard colicinogenic cultures to the lethal effects of their respective colicins, and of the resistance of known mutants of K12 to the action of specific colicins (Fredericq, 1948).

\section{Transfer of plasmids}

The conjugation techniques used were those of Anderson \& Lewis $(1965 a, b)$. Resistance transfer was detected by plating mating mixtures, generally after overnight incubation, on agar plates containing the appropriate drugs. Drugresistant donor strains of salmonellas in mating mixtures were suppressed with nalidixic acid (40 $\mu \mathrm{g} . / \mathrm{ml}$.$) , when the recipient strains were nalidixic acid-resistant$ mutants, or by spreading salmonella phage $\mathrm{O1}$ of Felix \& Callow (1943) on the surface of the agar before plating the cross (Anderson \& Lewis, 1965a,b). When the donor was K12 it was eliminated with colicin E2 (Anderson \& Lewis, 1965a,b).

\section{$R$ determinant mobilization}

The mobilizability of wild non-transferring $R$ determinants was tested with the triparental cross for determinant mobilization (Anderson, 1965a,b). Three transfer factors were routinely used for this purpose in the primary donor strains: the $f^{-}$ I-like $\Delta$ factor (Anderson \& Lewis, 1965b); the $f^{-}$I-like Coll factor ColIb-P9; and the $f^{-}$F-like transfer factor $X$ (Anderson, Pitton \& Mayhew, 1968). As results with $\Delta$ and the Coll factor were identical, ColI is not shown in Table 4.

\section{Phage multiplication}

Plasmids were examined for their ability to enable host strains to propagate the donor-specific phages $\mu 2$ and If1 by the method of Grindley \& Anderson (1971).

\section{Determination of compatibility group}

Plasmids were assigned to compatibility groups by examination of their ability to coexist with $R$ factors of the known compatibility groups (Grindley et al. 1972).

\section{Examination of fi character}

This character was routinely identified by examining the inhibition of visible lysis by the $\mathrm{F}$-specific phage $\mu 2$, which was spotted on surface cultures of $\mathrm{K} 12 \mathrm{~F}^{+}$ and K12HfrH into which plasmids had been introduced (Pitton \& Anderson, 1970). Factors that are $f^{+}$inhibit the synthesis of $\mathrm{F}$ fimbriae, which are the receptors for $\mathrm{F}$-specific phages. Thus, when $\mathrm{fi}^{+}$factors are introduced into strains carrying the $\mathrm{F}$ factor, such as $\mathrm{K} 12 \mathrm{~F}^{+}$and $\mathrm{K} 12 \mathrm{Hfr}$, they reduce or abolish visible lysis by these phages. In contrast, $f^{-}$plasmids do not affect $F$-fimbrial synthesis, and therefore do not affect lysis of $\mathrm{F}^{+}$or Hfr strains by $\mathrm{F}$-specific phages.

\section{Isolation and measurement of plasmid DNA}

Plasmid DNA was isolated, and the mean contour length (MCL) determined as described by Grindley et al. (1973). The molecular weight of the plasmids was calculated on the assumption that $1 \mu \mathrm{m}$. of DNA $=2.07 \times 10^{6}$ daltons (Lang, 1970). 
Table 2. Examination of the properties of transfer systems

Property Routine method of examination

Drug resistance

Colicinogeny :

Production

Identification

Transferability and frequency of transfer

Mobilization of non autotransferring resistance determinants

F and I fimbrial synthesis

Compatibility group

$f i$ character

Phage restriction:

In $\mathrm{K} 12$

In S. typhimurium

In S. typhi

In S. paratyphi B

Plasmid DNA characteristics

Degrees of drug resistance

Strip diffusion tests for

$\mathrm{A}, \mathrm{C}, \mathrm{K}, \mathrm{S}, \mathrm{T}$ and $\mathrm{G}$

Spot tests on solid media for

$\mathrm{Su}, \mathrm{Tm}, \mathrm{Fu}$ and $\mathrm{Nx}$

Sensitivity of K12 to colicins

Immunity and resistance of standard strains

Conjugation minant mobilization

Donor-specific phage multiplication

Ability to coexist with plasmids of defined groups and $\mathrm{K} 12 \mathrm{~F}^{+}$by phage $\mu \cdot 2$

Inhibition of lysis by phage $\phi 2$

Phage-typing

Phage-typing

Phage-typing

Isolation and measurement of plasmid DNA

Estimation of MICs of host
Fredericq (1948)

Fredericq (1948)

Anderson \& Lewis $(1965 a, b)$

Triparental cross for deter- Anderson (1965a,b)

Grindley \& Anderson (1971)

Grindley et al. (1972)

Inhibition of lysis of K12HfrH Pitton \& Anderson (1970) strains to the respective drugs in liquid and on solid media
Pitton \& Anderson (1970)

\{ Callow (1959)

Anderson (1964)

Craigie \& Yen $(1938 a, b)$

\{rajgie \& Felix (1947)

\{ Felix \& Callow $(1943,1951)$

Anderson (1964)

Grindley et al. (1973)

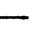

Drug resistance symbols: A, ampicillin; C, chloramphenicol; $\mathrm{K}$, neomycin-kanamycin; $\mathrm{S}$, streptomycin; Su, sulphonamides; G, gentamicin; T, tetracyclines; Tm, trimethoprim; Fu, furazolidone; Nx, nalidixic acid.

\section{Minimal inhibitory concentration (MIC)}

The MICs of strains carrying the ampicillin (A), chloramphenicol (C), streptomycin (S) and tetracycline (T) resistance determinants were estimated with doubling dilutions of the respective antibiotics in nutrient broth. A standard inoculum of approximately $10^{2}$ bacterial cells $/ \mathrm{ml}$. was used. The MIC was the lowest concentration of antibiotic that inhibited visible growth of the test strain in nutrient broth. Kanamycin MICs were similarly determined in Mueller-Hinton broth. Attempts were made to measure resistance to sulphonamides (sulpha- 
thiazole) on nutrient agar containing concentrations of the drug up to its limit of solubility ( $2000 \mu \mathrm{g}$. $/ \mathrm{ml}$.). The resistance always exceeded this concentration.

The methods for the examination of the properties of transfer systems are summarized in Table 2.

The identification of the spectrum of activity of plasmid-determined enzymes such as penicillinases and those for inactivation of streptomycin, and the serological specificity of such enzymes, are also methods of plasmid characterization that can be added when necessary. As a general rule, we have routinely used only the differentiation of streptomycin adenylylation from phosphorylation by inclusion of spectinomycin in tests of streptomycin resistance. Spectinomycin is inactivated only by adenylylation.

\section{RESULTS}

The sources and designations of nine transfer systems used to exemplify the methods of characterization are shown in Table 3. Their properties are summarized in Table 4.

\section{Drug resistance transfer}

In the $\Delta$ transfer systems, first identified in S. typhimurium type 29 ASSuTFu, strain RT1 (Anderson \& Lewis, 1965a,b), the $\Delta$ factor mediates independently the transfer of resistances to ampicillin, streptomycin-sulphonamides and tetracyclines. Furazolidone resistance has not yet been transferred.

The R factors TP110 (Anderson \& Smith, 1972a) and TP102 (Grindley \& Anderson, 1971), isolated from wild S. typhimurium strains 8M5251 and 8M5654, and the R factor TP114 (Grindley et al. 1972), from E. coli EC593, all carry a K determinant only; this codes for resistance to kanamycin, neomycin and paromomycin.

Factor 334 was isolated from a spontaneous kanamycin-sensitive segregant of S. paratyphi $B$ type 3a var. 4, 7R334. This strain was first characterized in the ERL in 1964. $R$ factor 334 transfers resistance to ampicillin, chloramphenicol, streptomycin and sulphonamides and, with the exception of loss of kanamycin resistance, is probably identical with the $R$ factor $R 1$, isolated from this strain by Meynell \& Datta (1966).

$\mathrm{R}$ factor TP123, isolated from S.typhi $1 \mathrm{~T} 4739$ (Anderson \& Smith, 1972b), transfers resistance to chloramphenicol, streptomycin-sulphonamides and tetracyclines. 1T4739 is representative of the strain responsible for a widespread outbreak of chloramphenicol-resistant typhoid fever, which started in Mexico early in 1972 and was still active in 1973.

TP118 (Anderson \& Threlfall, 1970) is an $R$ factor identified in S. enteritidis strain E3538, belonging to phage type 8. It confers resistance to ampicillin and streptomycin.

\section{Colicinogeny}

The Ib colicinogeny determinant is covalently bonded to the transfer factor in TP110, and transfers with kanamycin resistance (= KColIb) (Anderson \& Smith, $1972 a)$. No identifiable Col determinants are associated with the remaining eight transfer systems. 
Plasmid characterization

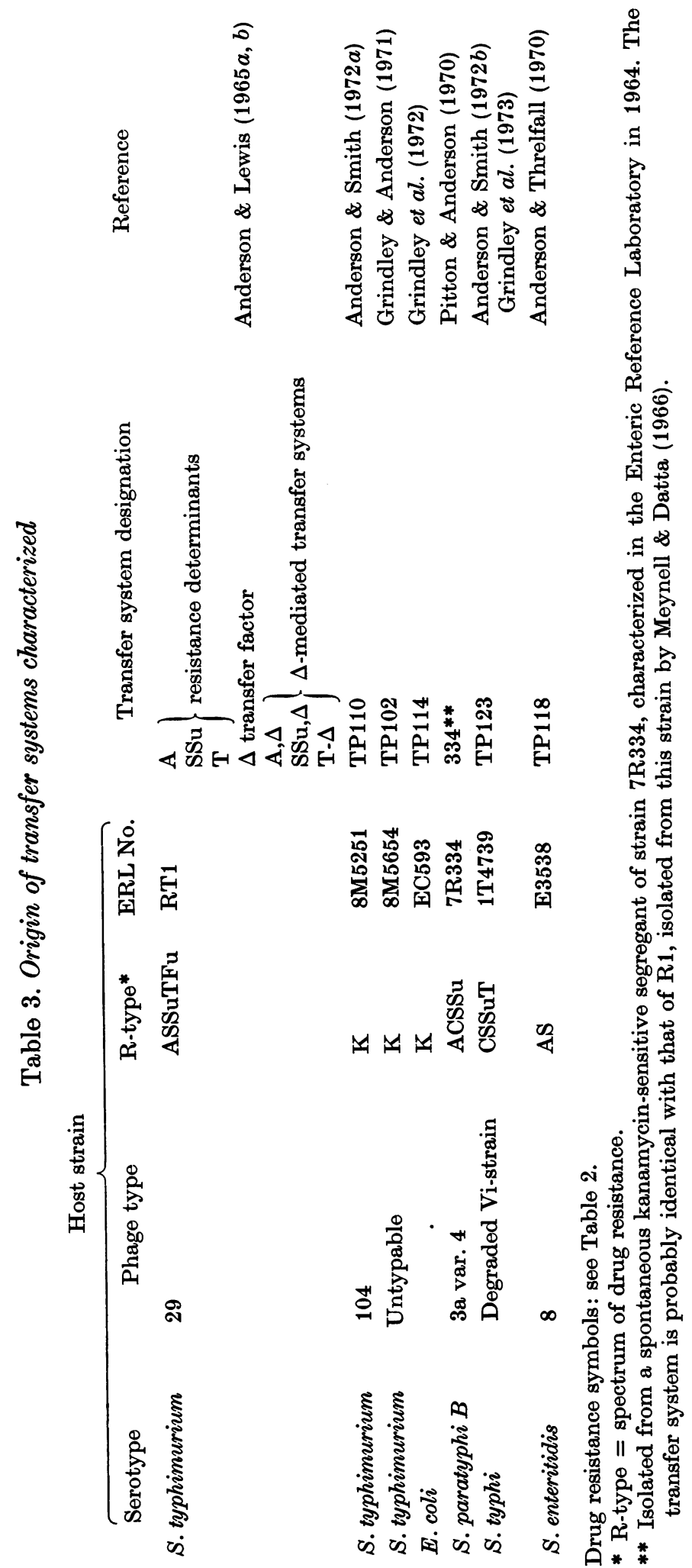



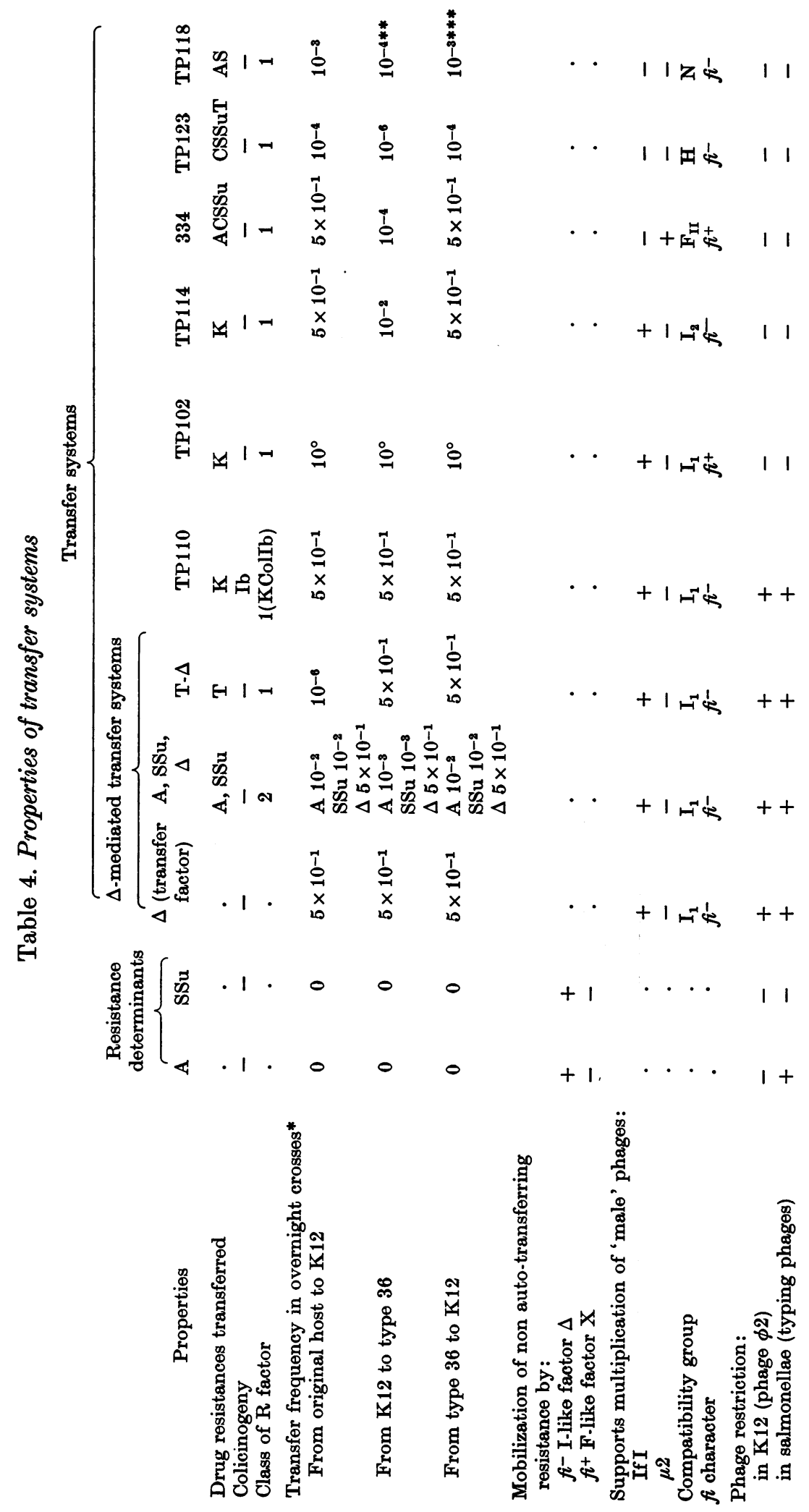


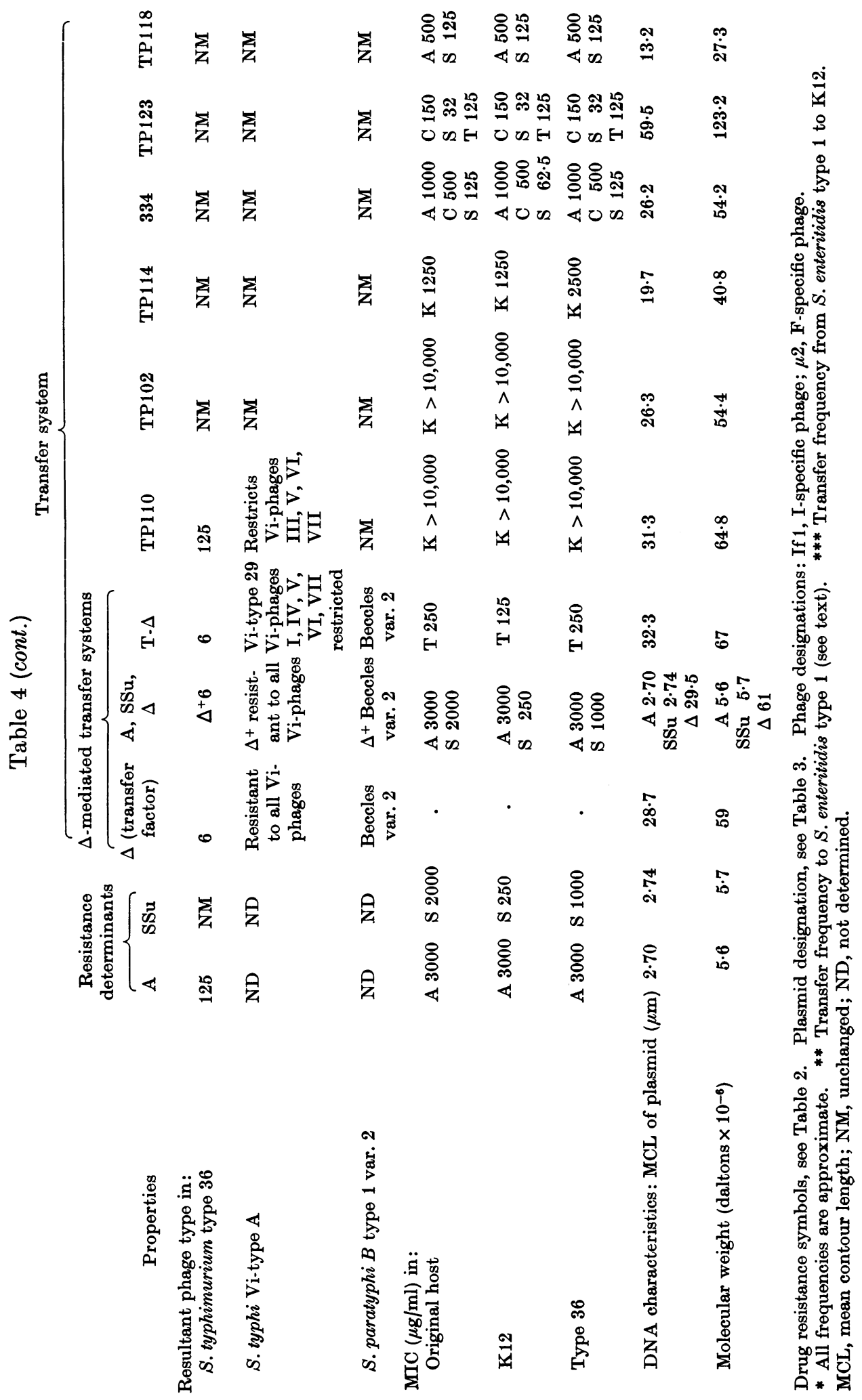




\section{Class of $R$ factor}

The tetracycline resistance determinant and $\Delta$ factor of the $\Delta$-mediated transfer system are covalently bonded to form a single plasmid which is transmitted as an intact linkage group, the Class $1 \mathrm{R}$ factor T- $\Delta$. A, $\Delta$ and SSu, $\Delta$ are Class 2 resistance transfer systems in which the A and SSu resistance determinants and the $\Delta$ transfer factor are independent of each other in the host cell. The plasmids of a Class 2 system may be transmitted simultaneously or separately (Anderson \& Lewis, $1965 a, b$; Anderson, 1968, 1969). The $\Delta$ factor is necessary for the transfer of the $\mathrm{A}$ and SSu determinants.

TP110, TP102, TP114, 334, TP123 and TP118 are Class $1 \mathrm{R}$ factors. The R determinants and transfer factors are transmitted together in these transfer systems. The respective $R$ determinants have not been found separately in exconjugants, although a low percentage of recipient cells may acquire only the transfer factor (Anderson \& Lewis, 1965b; Anderson, 1966).

\section{Transfer kinetics}

Since overnight crosses are routinely used in these investigations, transfer frequencies are estimated as a fraction of the total recipient population at the termination of the cross. All frequencies quoted are near approximations. The plasmids $\Delta, \mathrm{T}-\Delta$, TP110 and TP102, all transfer at high frequencies, up to $10^{\circ}$, in overnight crosses. The $A$ determinant of $A, \Delta$ transfers at lower frequency $\left(1^{-2}\right)$ than that of $\Delta$ alone (up to $10^{\circ}$ ) (Anderson \& Lewis, 1965b). The SSu determinant of RT1 behaves similarly to A. TP114 transfers at $5 \times 10^{-1}$ from $E$. coli EC593 to $\mathrm{K} 12$, and from K12 to type 36 at $10^{-2}$ or less. Type 36 transfers TP114 to K12 at $5 \times 10^{-1}$.

Factor 334 transfers at $5 \times 10^{-1}$ in crosses from S. paratyphi $B$ 7R334 and from type 36 to $\mathrm{K} 12$, but at only $10^{-4}$ from K12 to salmonella hosts.

TP123 transfers to K12 at $10^{-4}$ in crosses from S. typhi 1 T4739 and type 36 respectively, and at $10^{-6}$ or less from $\mathrm{K} 12$ to $S$. typhi and type 36 .

TP118 is relatively host specific: without modification this $\mathrm{R}$ factor will transfer only from S. enteritidis, in which it was first identified, to $S$. enteritidis $\left(10^{-4}\right)$ or to $\mathrm{K} 12\left(10^{-3}\right)$ and from K12 to S. enteritidis $\left(10^{-4}\right)$ (Anderson \& Threlfall, 1970). Transfer of N group plasmids from K12 to S. typhimurium often occurs at very low frequencies. For example, TP120 (Grindley et al. 1972, 1973) which has the resistance spectrum ASSuT, transfers to $S$. typhimurium 36 at about $10^{-6}$ in overnight crosses. TP120, and other group $\mathrm{N}$ plasmids isolated during the same period in 1962 (Anderson \& Datta, 1965) may lose resistance markers during transfer to S. typhimurium. Thus, TP120 may lose T or S during such transfer (Anderson \& Janet White, unpublished observations).

\section{Mobilization of non-transferring resistance determinants}

The $A$ and SSu determinants of the $\Delta$ transfer systems are plasmids that can be mobilized by I-like factors such as the $\Delta$ transfer factor and the ColI factor, but not by the F-like transfer factor $\mathrm{X}$. Thus, there is some specificity in determinanttransfer factor associations (Anderson, 1968). 
Host specificity may be an important character of some plasmids. For example, we have so far been unable to demonstrate transfer of $I_{1}$ plasmids to Proteus mirabilis PM1 (Anderson and Deniset, unpublished observations), although a number of F-like factors can enter that host.

\section{Donor-specific phage multiplication}

The transfer systems tested were grouped under three headings, as shown below :

1. F-like factors, which code for $F$ sex fimbriae, thereby enabling their hosts to propagate the $\mathrm{F}$-specific phages. $\mathrm{R}$ factor 334 belongs to this category.

2. I-like factors, which code for I sex fimbrial synthesis, enable their hosts to support multiplication of the I-specific phage If1. Examples are the transfer factor $\Delta$ and the R factors T- $\Delta$, TP110, TP102 and TP114.

3. Transfer systems that do not confer on their hosts the ability to propagate either F-specific or I-specific phages; for example, TP123 and TP118. This category is heterogeneous.

\section{Compatibility groups}

Transfer systems have been divided into compatibility groups (Romero, 1970; Khatoon \& Iyer, 1971; Hedges \& Datta, 1971; Datta \& Hedges, 1971; Chabbert et al. 1972; Grindley et al. 1972, 1973). In general, the members of each group are compatible with those of other groups, but are incompatible with each other.

As Table 4 shows, the I-like factors have been divided into the $I_{1}$ and $I_{2}$ compatibility groups. $\Delta$, TP110 and TP102 are incompatible with other I-like plasmids such as R144-3, and belong to the group designated $I_{1}$ by Grindley et al. (1972). However, TP114, which codes for the synthesis of I fimbriae, is compatible with the $I_{1}$ factor $T-\Delta$, and is the prototype of the $I_{2}$ group (Grindley et al. 1972).

The F-like $R$ factor 334 is an $F_{I I}$ plasmid which is compatible with $F_{I}$ factors such as the original F transfer factor (Hedges \& Datta, 1972). TP123 belongs to the $\mathrm{H}$ group (Anderson \& Smith, 1972b; Grindley et al. 1972, 1973), and TP118 to the $\mathrm{N}$ group (Grindley et al. 1972, 1973).

\section{The fertility inhibition (fi) character}

The $\mathrm{I}_{1}$ plasmids $\Delta, \mathrm{T}-\Delta$ and TP110, and the $\mathrm{I}_{2}$ plasmid TP114, are $f^{-}$: they do not inhibit visible lysis of strains of $\mathrm{K}_{12} \mathrm{~F}^{+}$or K12HfrH by the F-specific phage $\mu 2$. However, the $\mathrm{I}_{1} \mathrm{R}$ factor TP102 is $f^{+}$; it reduces lysis by phage $\mu 2$ and transfer of chromosomal characters by K12HfrH (Grindley \& Anderson, 1971).

The $\mathrm{F}_{\mathrm{II}} \mathrm{R}$ factor 334 is $f^{+}$(Pitton \& Anderson, 1970). Most wild $\mathrm{F}$-like factors show this character.

The H group plasmid TP123 and the N group plasmid TP118 are $f^{-}$.

\section{Phage restriction}

In $K 12$.

Of the $\mathrm{I}_{1}$ factors examined, the $f^{-}$plasmids $\Delta$, T- $\Delta$ and TP110 all reduce visible lysis of $\mathrm{K} 12$ by phage $\phi 2$. When the $\mathrm{K} 12$ strain carrying these factors is also $\mathrm{F}^{+}$or $\mathrm{Hfr}$, visible lysis by phage $\phi 2$ is abolished. In contrast, the $f^{+}$I-like 
$R$ factor TP102 is non-restricting for this phage. TP114, the $f^{-}$plasmid of the $I_{2}$ group, is also non-restricting for $\phi 2$ in $\mathrm{K} 12$, as are the $f^{+} \mathrm{F}_{\mathrm{II}} \mathrm{R}$ factor 334 and the $\mathrm{H}$ and N plasmids TP123 and TP118 respectively.

In S. typhimurium type 36, S. typhi Vi-type $A$ and S. paratyphi B 1 var. 2.

$\Delta$ transfer systems. $\mathrm{A}$ is one of the rare non auto-transferring resistance determinants so far observed to cause phage restriction (Anderson et al. 1968). It restricts phages 12 and 13 of the $S$. typhimurium typing scheme, thereby converting type 36 into type 125 (Anderson, 1966; Anderson et al. 1968). The SSu determinant does not cause phage restriction.

The $\Delta$ transfer factor and the T- $\Delta \mathrm{R}$ factor restrict the lysis of type 36 by 24 of the $30 \mathrm{~S}$. typhimurium typing phages, to produce type 6 (Anderson \& Lewis, 1965b). They convert $S$. paratyphi $B 1$ var. 2, which is sensitive to all 11 of the $S$. paratyphi $B$ typing phages, into phage type Beccles var. 2, sensitive to only 3 of the phages (Anderson, 1966). However, $\Delta$ differs from T- $\Delta$ in that it inhibits lysis of $S$. typhi type A by all 96 Vi-typing adaptations of Vi-phage II, whereas T- $\Delta$ converts type $A$ into type 29, which is sensitive to 13 of the adaptations (Anderson, 1966). Moreover, $\Delta$ also restricts lysis of $S$. typhi by the unadapted Vi-phages I, III, IV, V, VI and VII, whereas $S$. typhi type A carrying T- $\Delta$ remains sensitive to Vi-phage III (Anderson, 1966).

TP110 KColIb. TP110 converts type 36 of S.typhimurium into type 125, and is a representative of the $\Gamma$ group of transfer systems (Anderson et al. 1973). This $\mathrm{R}$ factor does not alter the Vi-type of $S$. typhi type A, but restricts the unadapted Vi-phages III, V, VI and VII of that host. It does not affect the phage type of $S$. paratyphi $B 1$ var. 2.

Other transfer systems. The I-like factors TP102 and TP114, the $\mathrm{F}_{\mathrm{II}} \mathrm{R}$ factor 334, the $\mathrm{H}$ plasmid TP123 and the N plasmid TP118, are all non-restricting in S. typhimurium type 36, S. typhi type A and S. paratyphi B 1 var. 2.

\section{Degrees of drug resistance}

$\Delta$ systems. The penicillin MIC of the wild host strain of S. typhimurium type 29, RT1, and of both type 36 and K12 carrying the A determinant, is $3000 \mu \mathrm{g} . / \mathrm{ml}$. (Anderson \& Lewis, 1965a; Anderson et al. 1968). The streptomycin MIC is $2000 \mu \mathrm{g} . / \mathrm{ml}$. in RT1, $1000 \mu \mathrm{g} . / \mathrm{ml}$. in type 36, and $250 \mu \mathrm{g} . / \mathrm{ml}$. in K12. The tetracycline MIC of strains carrying $\mathrm{T}-\Delta$ is $250 \mu \mathrm{g} . / \mathrm{ml}$. in the original host and in type 36 , and $125 \mu \mathrm{g} . / \mathrm{ml}$. in K12. Plasmid-borne tetracycline resistance is commonly of this magnitude.

TP110, TP102 and TP114. Kanamycin resistance. The kanamycin resistance in strains of S.typhimurium and K12 carrying TP110 and TP102 is greater than $10,000 \mu \mathrm{g} . / \mathrm{ml}$. In contrast, the MIC of kanamycin in strains carrying TP114 is $1,250 \mu \mathrm{g} . / \mathrm{ml}$. in both the original $E$. coli host and $\mathrm{K} 12$, and about $2,500 \mu \mathrm{g} . / \mathrm{ml}$. in type 36.

$R$ factor $334 A C S S u$. The ampicillin MIC of the original strain of S. paratyphi $B$ carrying 334 is $1000 \mu \mathrm{g} . / \mathrm{ml}$.; it is about the same in K12 and type 36. The chloramphenicol MIC of these strains is about $500 \mu \mathrm{g}$. $/ \mathrm{ml}$. The streptomycin MIC is 
$125 \mu \mathrm{g} . / \mathrm{ml}$. in S. paratyphi B and S. typhimurium, and $62.5 \mu \mathrm{g} . / \mathrm{ml}$. in K12. All host strains are resistant to at least $2000 \mu \mathrm{g} . / \mathrm{ml}$. of sulphathiazole, the limit of solubility of the drug.

TP123 CSSuT. TP123 confers a chloramphenicol MIC of $150 \mu \mathrm{g} . / \mathrm{ml}$. on its original host strain of S. typhi (Anderson \& Smith, 1972b), and on K12 and type 36. Its host strains also have MICs of $32 \mu \mathrm{g}$./ml. to streptomycin, and $125 \mu \mathrm{g} . / \mathrm{ml}$. to tetracycline. The sulphonamide MIC exceeds $2000 \mu \mathrm{g} . / \mathrm{ml}$.

TP118 AS. The ampicillin MIC of S.enteritidis, S.typhimurium and K12 carrying TP118 is $500 \mu \mathrm{g} . / \mathrm{ml} .$, and the streptomycin MIC, $125 \mu \mathrm{g} . / \mathrm{ml}$.

\section{DNA characteristics}

The DNA molecules of factors of a given compatibility group are of similar size, and usually of similar composition (Grindley et al. 1973). The group $\mathrm{I}_{1}$ factors, $\Delta$, T- $\Delta$, TP110 and TP102 have mean contour lengths (MCLs) of $28 \cdot 7,32 \cdot 3, * 31 \cdot 3$ and $26 \cdot 3 \mu \mathrm{m}$. respectively, corresponding to molecular weights of 59,67, 65 and $54 \times 10^{6}$ daltons. The prototype of the $I_{2}$ group is smaller, with a MCL of $19 \cdot 7 \mu \mathrm{m}$. and a molecular weight of $41 \times 10^{6}$ daltons. Although it codes for I fimbriae, it is distinct from plasmids of the $I_{1}$ group.

The $\mathrm{F}_{\mathrm{II}} \mathrm{R}$ factor 334 has a contour length of $26 \cdot 3 \mu \mathrm{m}$., corresponding to a molecular weight of $54 \times 10^{6}$ daltons. The contour length of the $\mathrm{H}$ group factor TP123 is $59.5 \mu \mathrm{m}$. and its molecular weight $123 \times 10^{6}$ daltons. The $\mathrm{N}$ group $\mathrm{R}$ factor TP118 is $13.2 \mu \mathrm{m}$. long, with a molecular weight of $27 \times 10^{6}$ daltons.

The non auto-transferring resistance determinants $\mathrm{A}$ and SSu are plasmids which are distinct from each other and from the compatibility groups described above. The mean contour length of $\mathrm{A}$ is $2.70 \mu \mathrm{m}$., and that of SSu $2.74 \mu \mathrm{m}$., corresponding to molecular weights of $5.6 \times 10^{6}$ and $5 \cdot 7 \times 10^{6}$ daltons respectively. Such determinants are present in multiple copies per chromosone, whereas only one copy of transferable plasmids is found.

\section{DISCUSSION}

We have described the properties of nine transfer systems in salmonellas and $E$. coli carrying resistance to various drugs. These systems have been divided into two classes according to the relationships between the $R$ determinants and the transfer factors (Anderson, 1968, 1969; Anderson \& Threlfall, 1970; Anderson \& Natkin, 1972; Humphreys $e t$ al. 1972). Seven of the transfer systems, T- $\Delta$, TP110, TP102, TP114, 334, TP123 and TP118, are Class $1 \mathrm{R}$ factors, that is, they are single covalently bonded plasmids which occupy the cellular attachment site of the respective transfer factor, and are transferred as intact linkage groups. Two, the $A, \Delta$ and SSu, $\Delta$ systems, belong to Class 2 , in which the $R$ determinants and the $\Delta$ transfer factor are distinct molecules, independent of each other and occupying separate attachment sites in the host cell : they are possibly associated only during transfer to a new host.

The $\mathrm{R}$ factor TP110 is a Class 1 system in which the kanamycin resistance

* The difference between the contour lengths of $\Delta$ and T- $\Delta, 3 \cdot 6 \mu \mathrm{m}$., gives an approximate length for the $T$ resistance determinant. 
determinant, the ColIb determinant and the I-like transfer factor are covalently bonded to form a single plasmid. Coll determinants are usually found in wild strains recombined with I-like transfer factors, and are common in S. typhimurium. Other Col determinants, such as E1 and E2, occur as independent non autotransferring plasmids, analogous to A and SSu (Anderson \& Lewis, 1965b).

Transferable plasmids can also be categorized according to the nature of the sex fimbrial synthesis they encode and by compatibility studies. Thus $\Delta, T-\Delta$, TP110 and TP102 are plasmids of the $I_{1}$ compatibility group, while TP114, although it supports multiplication of phage If 1 , is compatible with $I_{1}$ plasmids and is the prototype of the $I_{2}$ group (Grindley et al. 1972). $R$ factor 334 is an $F_{I I}$ plasmid, TP123 belongs to group H (Anderson \& Smith, 1972b; Grindley et al. 1972) and TP118 to group N.

Molecular characterization of plasmid DNA confirms the groupings obtained by genetic analysis. The contour lengths of plasmids of the $I_{1}$ group are similar (average contour length $29.7 \mu \mathrm{m}$.) and differ substantially from that of the $I_{2}$ plasmid TP114 (contour length $19 \cdot 7 \mu \mathrm{m}$.). The contour lengths of TP118, the $\mathrm{N}$ group plasmid $(13.2 \mu \mathrm{m}$.), and TP123, the $\mathrm{H}$ plasmid $(59.5 \mu \mathrm{m}$.), are also quite distinct from each other and from $I_{1}$ and $I_{2}$ plasmids (Grindley et al. 1973).

DNA reassociation of high degree usually occurs between plasmids of a single compatibility group, but not between those of different groups (Grindley et al. 1973). For example, reassociation readily takes place between the DNA of different $I_{1}$ plasmids, but not between plasmids of this group and the DNA of the $I_{2}$ plasmid TP114, or that of plasmids of other compatibility groups. However, some plasmids may be atypical. Thus, no reassociation could be demonstrated between the DNA of TP116, an $\mathrm{H}$ group $\mathrm{R}$ factor, and that of other $\mathrm{H}$ group plasmids (Grindley et al. 1973). Incompatibility, therefore, may not necessarily indicate molecular similarity.

Plasmids of a given compatibility group have similar transfer kinetics, which often differ from those of other groups. For example, the $I_{1}$ plasmids we have studied invariably transfer at high frequencies (up to $10^{\circ}$ ) in overnight crosses, whereas the $\mathrm{H}$ plasmid TP123 transfers at low frequencies, about $10^{-4}$ into K12, and as low as $10^{-6}$ into S. typhimurium and S. typhi. These low transfer frequencies are a feature of all $\mathrm{H}$ group plasmids so far examined.

It is worth noting that members of the same compatibility group may carry different resistance determinants in a Class 1 association, and, conversely, that members of different groups may carry determinants coding for similar resistances. Resistance markers are therefore of limited value in the identification of $\mathbf{R}$ factors. Thus, the Class $1 \mathrm{R}$ factor in the strain of Shigella dysenteriae 1, which caused the huge dysentery outbreak in Central America from 1968 onwards, codes for resistance to chloramphenicol, streptomycin, sulphonamides and tetracyclines, and belongs to compatibility group B. The strain of $S$. typhi that caused the widespread typhoid outbreak in Mexico in 1972 is resistant to the same drugs, but belongs to group $\mathrm{H}$ (Grindley et al. 1972). These two $\mathrm{R}$ factors are thus quite distinct from each other, despite the similarity of their resistance markers.

The $\mathrm{fi}^{+}$character (Egawa \& Hirota, 1962; Watanabe \& Fukasawa, 1962; Watanabe, 1963; Watanabe et al. 1962, 1964) has now been identified in several 
groups of plasmids. Although most $\mathrm{I}_{1}$ and $\mathrm{N}$ factors are $\mathrm{fi}^{-}, \mathrm{fi}^{+}$factors of these groups have been identified (Grindley \& Anderson, 1971; Grindley et al. 1973). However, all wild $\mathrm{F}_{\mathrm{II}} \mathrm{R}$ factors so far examined are $f^{+}$.

Plasmids within a single compatibility group can be subdivided by their phagerestrictive effects in K12 and in salmonellas. $f^{-}$I-like $\mathrm{R}$ factors and transfer factors have been divided into eleven types by their typing phage restriction in $S$. typhimurium (Anderson et al. 1973). Further subdivision may be possible by the determination of phage restriction in S. typhi and S. paratyphi B (Anderson, 1966). The $\mathrm{F}$ factor of K12 restricts one $S$. typhimurium typing phage (Anderson et al. 1973) and unadapted Vi-phages III, V, VI and VII of the S. typhi Vi-typing scheme.

Non-transferring resistance determinants can be characterized by the specificity of their mobilization by transfer factors: for example, SSu determinants are in general most easily mobilized by I-like factors. The degrees of resistance they confer on their host strains may also be characteristic. Only resistance determinants from Class 2 systems can be characterized by their mobilization specificity, since they can be isolated without transfer factors in the host cell.

The foregoing description outlines the methods currently used in the Enteric Reference Laboratory for the characterization of transfer systems in the enterobacteria. These methods are useful for classifying the systems on the basis of their genetic properties and molecular structure, and may ultimately expose their origins and host relationships in man and animals.

We are indebted to the Department of Health for a grant in support of this research.

\section{REFERENCES}

Anderson, E. S. (1964). In The World Problem of Salmonellosis, p. 89 (Ed. E. Van Oye). The Hague: Dr W. Junk.

ANDERson, E. S. (1965a). Origin of transferable drug-resistance factors in the Enterobacteriaceae. British Medical Journal ii, 1289.

ANDERSON, E. S. (1965 b). A rapid screening test for transfer factors in drug-sensitive Enterobacteriaceae. Nature, London 208, 1016.

ANDERSon, E. S. (1966). Influence of the $\Delta$ transfer factor on the phage sensitivity of Salmonellae. Nature, London 212, 795.

Anderson, E. S. (1968). The ecology of transferable drug resistance in the enterobacteria. Annual Review of Microbiology 22, 131.

Anderson, E. S. (1969). In Ciba Foundation Symposium on Bacterial Episomes and Plasmids, p. 102 (Ed. G. E. W. Wolstenholme and M. O'Connor). London: J. and A. Churchill Ltd.

Anderson, E. S. \& DatTa, N. (1965). Resistance to penicillins and its transfer to Enterobacteriaceae. Lancet ii, 407.

Anderson, E. S. \& Lewis, M. J. (1965a). Drug resistance and its transfer in Salmonella typhimurium. Nature, London 206, 579.

Anderson, E. S. \& LEwIs, M. J. (1965b). Characterisation of a transfer factor associated with drug resistance in Salmonella typhimurium. Nature, London 208, 843.

Anderson, E. S. \& Natkin, E. (1972). Transduction of resistance determinants and $R$ factors of the $\Delta$ transfer system by phage P1kc. Molecular and General Genetics 114, 261.

Anderson, E. S., Pitton, J-S. \& Mayhew, J. N. (1968). Restriction of bacteriophage multiplication by resistance determinants in Salmonellae. Nature, London 219, 640.

ANDERson, E. S. \& Smith, H. R. (1972a). Fertility inhibition in strains of Salmonella typhimurium. Molecular and General Genetics 118, 79.

Anderson, E. S. \& Smith, H. R. (1972b). Chloramphenicol resistance in the typhoid bacillus. British Medical Journal iii, 329. 
Anderson, E. S. \& Threlfall, E. J. (1970). Change of host range in a resistance factor. Genetical Research 16, 207.

Anderson, E. S., Threlfall, E. J., Carr, J. M. \& Savoy, L. G. (1973). Bacteriophage restriction in Salmonella typhimurium by $\mathbf{R}$ factors and transfer factors. Journal of Hygiene 71, 619.

ANDERSON, E.S. \& Williams, R. E. O. (1956). Bacteriophage typing of enteric pathogens and staphylococci and its use in epidemiology. Journal of Clinical Pathology 9, 94.

CALLOW, B. R. (1959). A new phage-typing scheme for Salmonella typhimurium. Journal of Hygiene 57, 346.

Chabbert, Y. A., Scavizzi, M. R., Witchitz, J. L., Gerbaud, G. R. \& Bouanchaud, D. H. (1972). Incompatibility groups and the classification of $f^{-}$resistance factors. Journal of Bacteriology 112, 666.

Cratgre, J. \& Felix, A. (1947). Typing of typhoid bacilli with Vi bacteriophage. Lancet i, 823.

CraIfIE, J. \& YEN, C. H. (1938a). The demonstration of types of B. typhosus by means of preparations of Type II Vi-phage. 1. Canadian Journal of Public Health 29, 448.

CRAIGIE, J. \& YEN, C. H. (1938b). The demonstration of types of B. typhosus by means of preparations of Type II Vi-phage. 2. Canadian Journal of Public Health 29, 484.

Cuzrn, F. (1965). Un bactériophage spécifique du type sexuel $\mathrm{F}^{-} d^{\prime}$ Escherichia coli K12. Comptes Rendus de l'Académie des Sciences, Paris 260, 6482.

Datta, N. \& Hedges, R. W. (1971). Compatibility groups among $f^{-}$R factors. Nature, London 234, 222.

Dettori, R., Maccacaro, G. A. \& Piccinin, G. L. (1961). Sex-specific bacteriophages of Escherichia coli K12. Giornale di Microbiologia 9, 141.

Egawa, R. \& HIROTA, Y. (1962). Inhibition of fertility by multiple drug resistance factor (R) in Escherichia coli K12. Japanese Journal of Genetics 37, 66.

Felix, A. \& Callow, B. R. (1943). Typing of paratyphoid B bacilli by means of Vi bacteriophage. British Medical Journal ii, 127.

Felix, A. \& Callow, B. R. (1951). Paratyphoid B Vi-phage typing. Lancet ii, 10.

Fredericq, P. (1948). Actions antibiotiques réciproques chez les Entérobactériaceae. Revue belge de Pathologie et de Médecine expérimentale, 19, supplément IV, 1.

FredericQ, P. (1956). Recherches sur la fréquence des souches transductrices des propriétés colicinogènes. Comptes rendus des séances de la Société de Biologie et de ses Filiales, Paris 150, 1036.

Grindley, J. N. \& ANDerson, E. S. (1971). I-like resistance factors with the $f^{+}$character. Genetical Research 17, 267.

Grindley, N. D. F., Grindley, J. N. \& Anderson, E. S. (1972). R factor compatibility groups. Molecular and General Genetics 119, 287.

Grindley, N. D. F., Humphreys, G. O. \& Anderson, E. S. (1973). Molecular studies of $\mathrm{R}$ factor compatibility groups. Journal of Bacteriology 115, 387.

Hedges, R. W. \& DATTA, N. (1971). $f^{-} \mathbf{R}$ factors giving chloramphenicol resistance. Nature, London 234, 220.

Hedges, R. W. \& DatTa, N. (1972). R124, an $f^{+} R$ factor of a new compatibility class. Journal of General Microbiology 71, 403.

Humphreys, G. O., Grindley, N. D. F. \& ANDerson, E. S. (1972). DNA-protein complexes of $\Delta$-mediated transfer systems. Biochemica et Biophysica Acta 287, 335.

KHAtoon, H. \& IyeR, R. V. (1971). Stable coexistence of R fi- factors in Escherichia coli. Canadian Journal of Microbiology 17, 669.

LANG, D. (1970). Molecular weights of coliphages and coliphage DNA. III. Contour length and molecular weight of DNA from bacteriophages T4, T5 and T7, and from bovine papilloma virus. Journal of Molecular Biology 54, 557.

Meynell, E. \& DatTa, N. (1966). The relation of resistance transfer factors to the F-factor (sex factor) of Escherichia coli K12. Genetical Research 7, 134.

MeYnele, E. \& Datta, N. (1967). Mutant drug resistance factors of high transmissibility. Nature, London 214, 885.

Meynell, G. G. \& Lawn, A. H. (1968). Filamentous phages specific for the I sex factor. Nature, London, 217, 1184.

Pitton, J.-S. \& Anderson, E. S. (1970). The inhibitory action of transfer factors on lysis of Escherichia coli K12 by phages $\mu 2$ and $\phi 2$. Genetical Research 16, 215. 
Journal of Hygiene, Vol. 72, No. 3

Plate 1

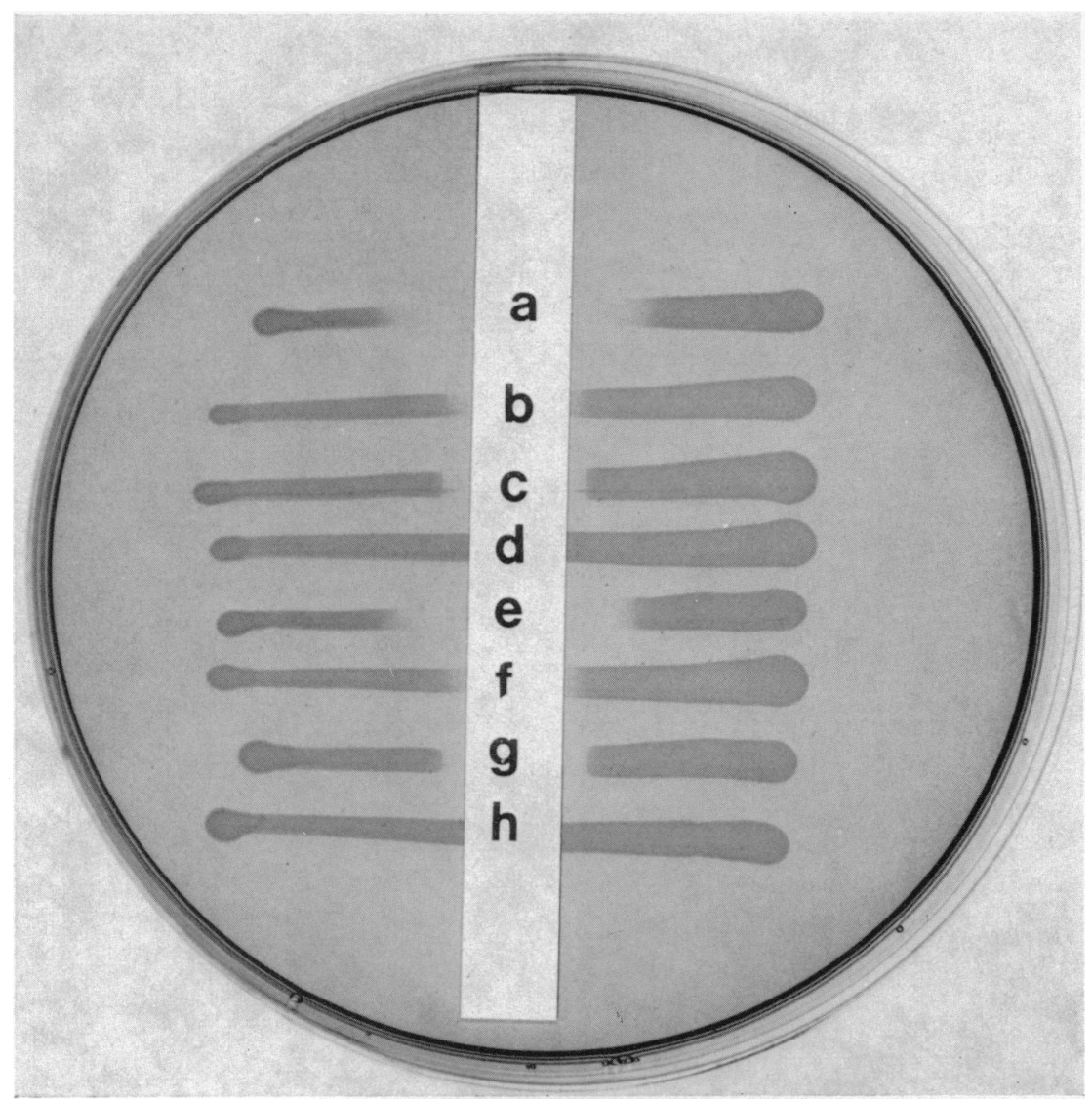

E. S. ANDERSON AND E. J. THRELFALL 
Journal of Hygiene, Vol. 72, No. 3

Plate 2
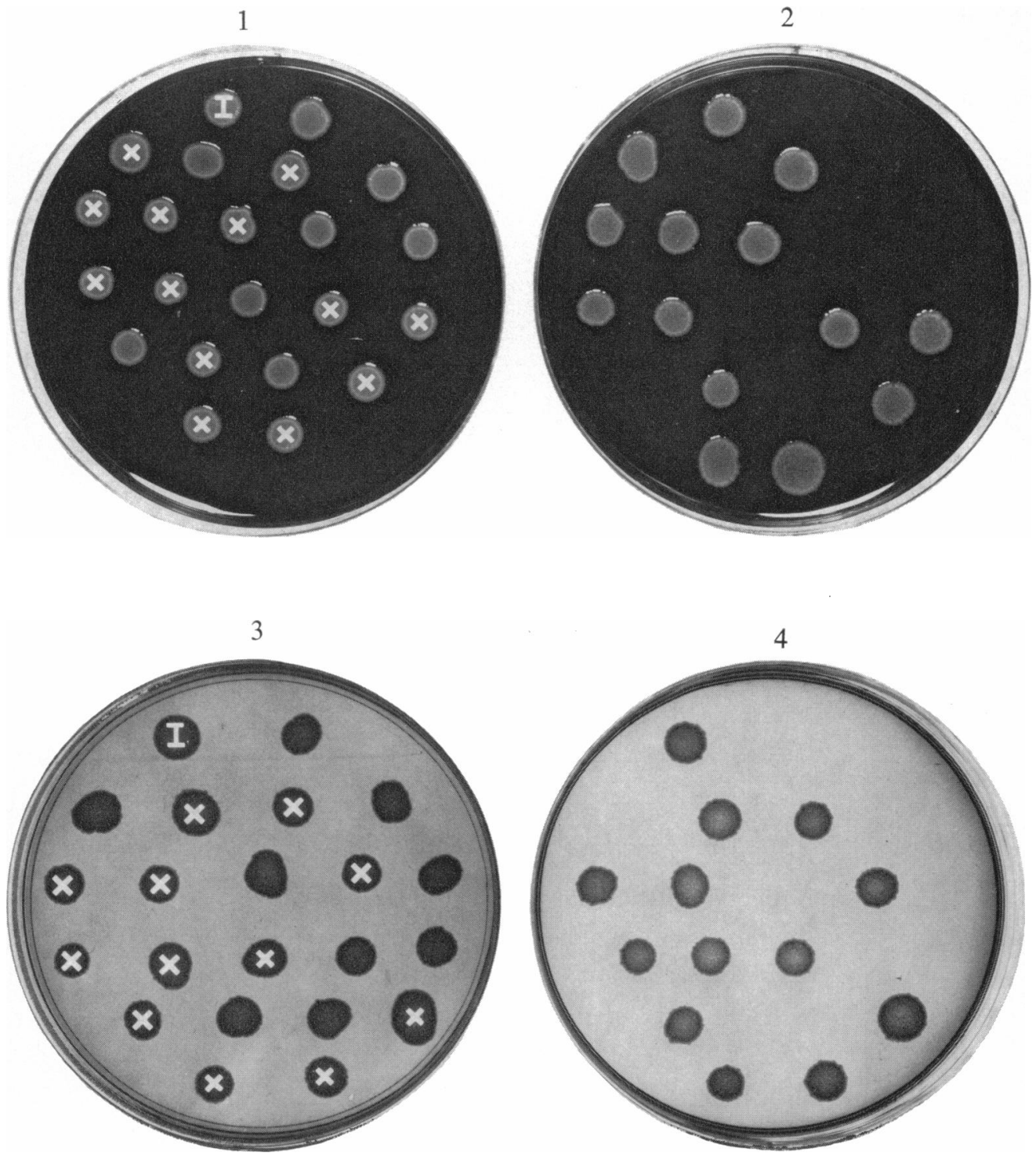

E. S. ANDERSON AND E. J. THRELFALL 
Romero, E. (1970). Two classes of $f^{-} \mathbf{R}$ factors. Bollettino dell'Instituto Sieroterapico Milanese 49, 484.

WatanaBe, T. (1963). Infective heredity of multiple drug resistance in bacteria. Bacteriological Reviews 27, 87.

Watanabe, T. \& Fukasawa, T. (1962). Episome-mediated transfer of drug resistance in Enterobacteriaceae. IV. Interactions between resistance transfer factor and F-factor in Escherichia coli K12. Journal of Bacteriology 83, 1727.

Watanabe, T., Fukasawa, T. \& Takano, T. (1962). Conversion of male bacteria of Escherichia coli $\mathrm{K} 12$ to resistance to $\mathrm{F}$ phages by infection with the episome 'Resistance Transfer Factor'. Virology 17, 217.

Watanabe, T., Nishida, H., Ogata, C., Arai, T. \& Sato, S. (1964). Episome-mediated transfer of drug resistance in Enterobacteriaceae. VII. Two types of naturally occurring $\mathrm{R}$ factors. Journal of Bacteriology 88, 716.

\section{EXPLANATION OF PLATES}

Plate 1

Resistance typing by strip-diffusion method. The central blotting-paper strip is impregnated with ampicillin Cultures $(a)-(d)$ have the following MICs $(\mu \mathrm{g} . / \mathrm{ml}):.(a) 4$ (sensitive control); (b) $32 ;(c) 16 ;(d) 500 .(e)(f)(g)$ and $(h)$ are duplicates of $(a),(b),(c)$ and $(d)$.

\section{Plate 2}

Figs. 1 and 2. Sulphonamide resistance testing. In Fig. 1 the plate contains nutrient agar with $5 \% \mathrm{v} / \mathrm{v}$ lysed horse blood. In Fig. 2 the plate contains the same medium $+100 \mu \mathrm{g} . / \mathrm{ml}$. sulphathiazole. Cultures marked with crosses in Fig. 1 are sulphonamide-resistant. I = resistant control.

Figs. 3 and 4. Nalidixic acid resistance testing. In Fig. 3 the plate contains nutrient agar, and in Fig. 4 nutrient agar with $40 \mu \mathrm{g} . / \mathrm{ml}$. nalidixic acid. Cultures marked with crosses in Fig. 3 are nalidixic acid resistant. $\mathrm{I}=$ resistant control. 